\title{
Image Processing Techniques for Maintenance of Roads
}

\author{
${ }^{1}$ Ankita Khatri and ${ }^{2}$ Dr. Umesh Sharma
}

\begin{abstract}
The increasing number of vehicles on roads drives a need of preserving road network in good condition thereby improving the performance of the existing roads. Road performance can be monitored by observing its structural and functional performance or predicting the serviceability of a road from its initial service time to the desired evaluation time. Generally, road condition can be evaluated on the basis of four aspects i.e. riding quality, surface distress, structural capacity and skid resistance. In a road maintenance management system, the assessment of road surface distresses is one of the important tasks for developing repair and maintenance strategies. In the past few years, various image processing techniques have been developed for the detection of distresses like potholes, patches, cracks etc on the road surface. However, the effective use of these methods for the characterization of various distresses on roads particularly in Indian conditions is yet to be established. The aim of the present paper is to provide an overview of implementation of various image processing techniques for the detection and characterization of road distresses.
\end{abstract}

Keywords- Road, Distress, Assessment, Image
processing.

\section{INTRODUCTION}

The quality and efficiency of road transportation plays a vital role in economic development of any country. In India, road transport occupies a dominant position in the overall transportation system as compared to the other modes of transportation of the country, due to its advantages like easy availability, flexibility of operation, door to door service and reliability. As per the statistics of the year 2014, India owns the second largest network of roads in the world, next to USA with a total road length of about 5.3 million kilometers [1].

The increasing urban population in rapidly expanding cities has further resulted in growing urban travel demand. As per the 2011 census, the urban population in India in 2011 was 377 million, constituting 31.2 per cent of the total population. It grew from 159 million in 1981[2]. It is projected to grow to 820 million by 2051 [3]. There is a tremendous increase in the total number of registered motor vehicles in India from about 5.4 million as on 31st March, 1981 to 172.9 million as on 31st March, 2014 [1],[3]. The total registered vehicles in the country grew at a Compound Annual Growth Rate (CAGR) of 11.07 per cent between 1981 and 2014 .

Manuscript received July. 2, 2016.

${ }^{2}$ Dr. Umesh Sharma is associate professor at PEC University of Technology, Chandigarh, 160012, India.

${ }^{1}$ Ms. Ankita Khatri is Ph.D scholar at PEC University of Technology, Chandigarh, 160012, India.
The increasing number of vehicles on roads drives a need of preserving road network in good condition thereby improving the performance of the existing roads. Performance of a road network can be monitored by observing its structural and functional performance or predicting the serviceability of a pavement from its initial service time to the desired evaluation time. Generally, road condition can be evaluated on the basis of four aspects i.e. riding quality, surface distress, structural capacity and skid resistance. The failure or deterioration of pavement occurs due to various factors like age, traffic, environment, material properties, pavement thickness, strength of pavement as well as subgrade properties which affect the mechanical characteristics of a pavement. In a road maintenance management system, the assessment of road surface distresses is one of the important tasks for developing repair and maintenance strategies [4].

The four major categories of surface distresses of bituminous roads are [5],[6]:

1. Cracking

2. Surface deformation

3. Disintegration (eg. potholes, etc.)

4. Surface defects (eg. bleeding, etc.)

The types of distress under each category are given in table I.

TABLE I: TYPES OF DISTRESS IN BITUMINOUS ROAD

\begin{tabular}{|l|l|l|l|}
\hline \multicolumn{1}{|c|}{ Cracking } & $\begin{array}{l}\text { Surface } \\
\text { Deformation }\end{array}$ & Disintegration & $\begin{array}{l}\text { Surface } \\
\text { Defects }\end{array}$ \\
\hline Fatigue cracking & Rutting & Potholes & Ravelling \\
Longitudinal & Corrugations & Patches & Bleeding \\
cracking & Shoving & & Polishing \\
Transverse cracking & Depressions & & Delamination \\
Block cracking & Swell & & \\
Slippage cracking & Upheaval & & \\
Reflective cracking & & & \\
Edge cracking & & & \\
Diagonal Cracking & & & \\
\hline
\end{tabular}

For proper road maintenance operation, it is therefore important to first identify the type of distress present on the road and then provide suitable remedial measure.

In the current field practices, road distress data assessment is done in many ways, which may be grouped into three categories depending upon the techniques or methods employed viz. manual, sensor and imaging based systems [7],[8].

At present, distress data collection is increasingly being automated by using various imaging systems. However, analysis of the collected raw video images for distress assessment is still predominantly being done manually. This is expensive, time consuming and slows down the road maintenance management.

In the past few years, various automated methods have been developed for the identification of some of the distresses like 
potholes, patches, cracks on the road surface using various image processing techniques [9], [10], [11], [12]. The application of these methods has shown encouraging results. However, the effective use of image processing techniques for the characterization of various distresses on roads, particularly in India is yet to be established.

\section{LITERATURE REVIEW}

\section{A. For Crack Detection (Linear Feature)}

[13] proposed a method for detection and characterization of cracks (linear features) on road surface using various image processing techniques. The methodology was divided into the following steps: 1) Image enhancement, 2) Attribute extraction, 3) Crack type characterization, 4) Assigning the severity level.

Image enhancement was done using image normalization method so as to reduce non uniform background illumination. For attribute extraction, images were separated into image blocks. Mean and Standard deviation values were obtained for each block. Finally, the $\mathrm{K}_{\text {mean }}$ clustering algorithm was applied for the crack detection and characterization (Fig. 1). For assigning the severity level [14] to the cracks detected, Otsu's gray thresholding method was used. The performance of the method was assessed by manually inspecting the pavement and the results of the manual analysis were compared with the results of the proposed approach.

The results showed that out of 50 images, images without cracks were 10 , images with transversal crack were 10 , images with longitudinal cracks were 7 and images with miscellaneous cracks were 9. The accuracy was not determined for the proposed method.

The study was confined to the detection and characterization of linear features only and the detection and characterization of area features was not included.

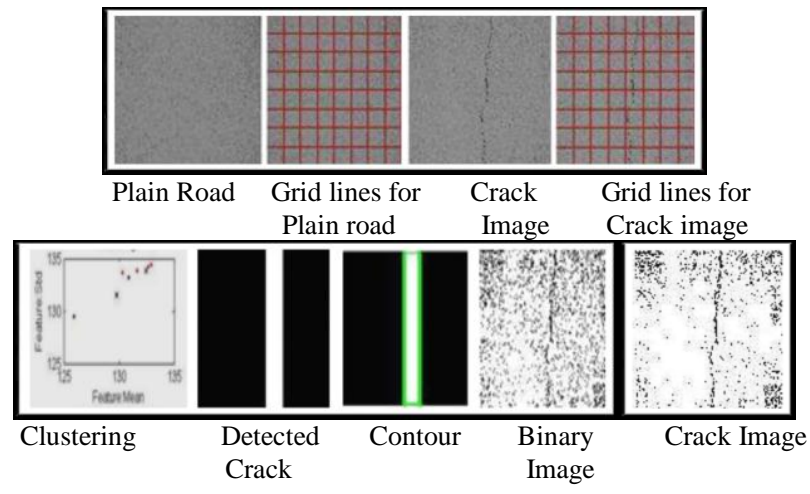

Fig. 1: Methodology used for crack detection [13]

\section{B. For Pothole Detection (Area Feature)}

[12] proposed a method for the detection of pothole (area feature) from road surface images. The videos of road surface were captured by a remote-controlled robot vehicle equipped with a camera. The distinctive visual characteristics (shadow, shape and texture) of a pothole (area feature) were utilized for the detection method, which was divided into (1) image segmentation, (2) shape extraction, and (3) texture extraction (Fig. 2). The performance evaluation of the proposed method was done by calculating the precision, recall and accuracy for the method.

It was seen from the results that out of 70 images, 30 images contained one or two potholes, 13 images had cracks, 5 images had repair patches, 7 images showed several discoloration spots, 4 images had dark spot shadows, 1 image contained a manhole cover, and 10 images with no distress. The accuracy of $86 \%$ was obtained, along with $82 \%$ precision and $86 \%$ recall. The result indicated that most area features (potholes) in bituminous road images can be correctly detected.
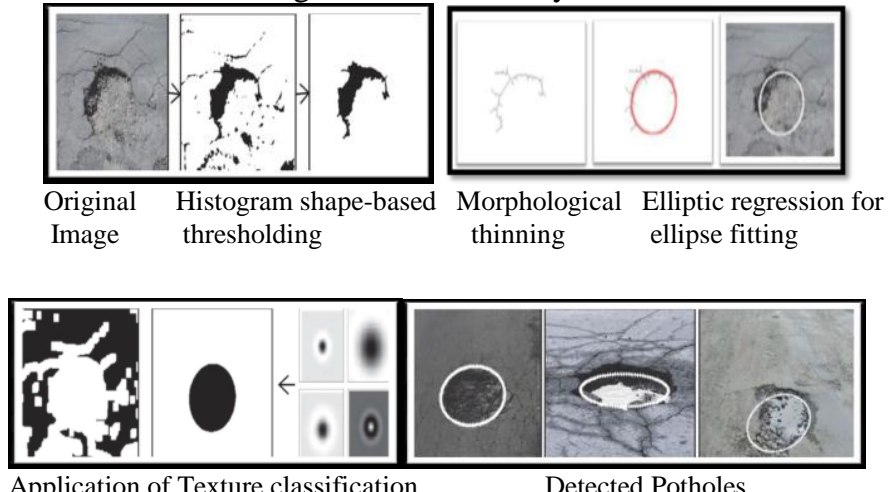

Application of Texture classification

Detected Potholes Filter banks

Fig. 2: Methodology used for potholes detection [12]

\section{For Patch Detection (Area Feature)}

[15] proposed a method for detection of patches on bituminous road surface. The techniques used were histogram equalization for image enhancement, morphological operations for identifying the boundary of the patch and application of texture filters for the extraction and comparison of texture of pavement with patch (Fig. 3). The proposed detection method was first tested using 70 images out of which 58 included patch. The total number of patches included in these images was 63 . The performance was measured by comparing the proposed method results with the ones produced by manually identifying the ground truth.

It was found that the detection algorithm had detection accuracy of $75 \%$ with $82 \%$ precision and $86 \%$ recall. Although the results showed that the proposed method is promising and has high potential. But the study was limited to the detection of patches only, the quantification of patches and the detection and characterization of any other distress was not included in the study.

The above proposed methods implemented for the detection of cracks, potholes and patches are based on pixel based image analysis. Most of the image processing techniques based on pixel based image analysis consider only spectral information and thus may have limitations in detecting all types of road distresses.

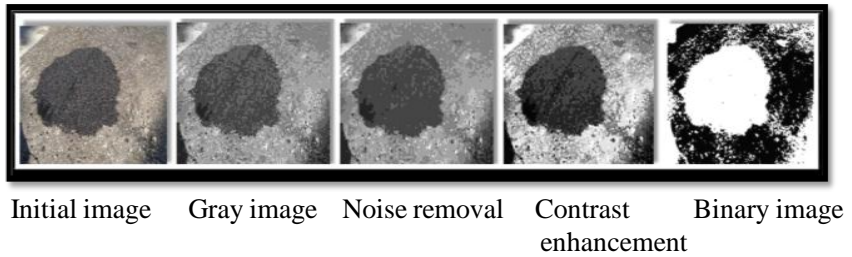




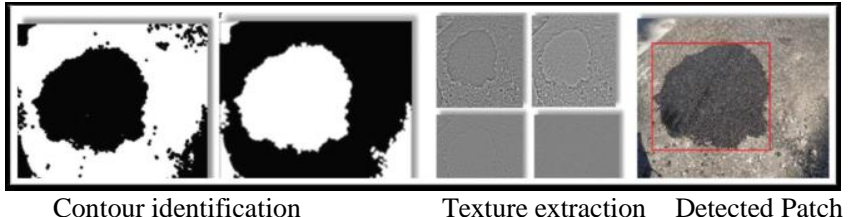

Fig. 3: Methodology used for patch detection [15]

\section{APPLICATION OF OBIA (OBJECT BASED IMAGE ANALYSIS) FOR ROAD DISTRESS ASSESSMENT}

[16] proposed a method for detection and classification of roads and vehicles from high resolution satellite image using Object Based image analysis (OBIA). The study concluded that the pixel based image analysis largely neglects the spatial attributes such as texture, context and shape whereas the object based approach not only allows the user to work with large number of attributes but also provides the ability to include the user knowledge into the software based interpretation process. These extra types of information give OBIA the potential to produce results with higher accuracies than those produced by traditional pixel based approach.

From the literature, it can be seen that no work has been done using Object Based image analysis for the detection and characterization of linear (crack) and area features (potholes, patches, delamination) of roads from ground images. Thus, the usefulness of OBIA in classifying roads from satellite images can be further extended to detect road distress types from images acquired from moving ground vehicles.

\section{CONCLUSION}

The brief overview of the results from different researchers on detection of road distresses clearly indicate that,

- Very few studies on identification and detection of road distresses using image processing on Indian roads have been observed. Most of the work in this direction is carried out manually.

- Image processing techniques have lot of potential in effectively detecting the potholes, cracks and patches from images extracted from cameras fitted in moving ground vehicles. These techniques have been limited to detection of cracks, potholes and patches, and not much work has been done on the detection of other bituminous road distresses. Therefore, the detection of other types of road distresses needs to be explored further.

- Majority of image processing techniques for the detection and characterization of linear (e.g., cracks) and area objects (e.g., potholes, delamination, and patches) are pixel based.

- The application of Object Based Image Analysis (OBIA) can be seen for the detection of roads using satellite images. However, no work has been done using Object Based image analysis for the detection and characterization of linear and area features of roads from ground images. Thus, the potential of OBIA for detection and characterization of road distress types from ground images can be further explored.

- It is believed that the advantages of OBIA in treating each road distress as an object and including geometric and textural characteristics in addition to spectral characteristics will improve in the accuracy of detection of road distresses.

\section{REFERENCES}

[1] MOSPI (2015). "India in Figures." Ministry of Statistics and Programme Implementation, Government of India, New Delhi, pp 1 and 13.

[2] Chandramouli C. (2011). "Rural Urban Distribution of Population." Ministry of Home Affairs, New Delhi, pp. 3-7.

[3] MORTH (2012). "Road transport year book." Transport research wing ministry of road transport \& highways, government of India, New Delhi, pp. 7-11.

[4] MORTH (2004). "Guidelines for Maintenance Management of Primary, Secondary and Urban Roads." Ministry of Transport and Highway, Indian Road Congress, New Delhi, pp. 3.

[5] MORTH (2001). "Manual for construction and supervision of bituminous works." Ministry of Transport and Highway, Indian Road Congress, New Delhi, pp 220-244.

[6] Adlinge S. S., Gupta A.K. (2013). "Pavement Deterioration and its Causes." International Journal of Pavement Research and Technology, 4(4), pp. 195-202.

[7] McGhee H.K (2004). "Automated pavement distress collection techniques." Transportation Research Board, NCHRP Synthesis 334, National Research Council, Washington, pp 334.

[8] Bennett C.R., Chamorro A., Chen C., Sominihac H.D., Flintsch G.W. (2007). "Data collection for road management." Report no. 2, East Asia Pacific Transport Unit, Washington, pp. 5-9.

[9] Acosta J. A., Figueroa J. L, Mullen R.L. (1995). “Algorithm for Pavement Distress Classification by Video Image Analysis." Transportation Research Board, 1505, pp. 27-38.

[10] Pynn J., Wright A., Lodge R. (1999). "Automatic identification of cracks in road surfaces." Proceedings of the $7^{\text {th }}$ International Conference on Image Processing and Its Applications, Manchester, July 13-15, 2, pp. 2. http://dx.doi.org/10.1049/cp:19990408

[11] Sy N. T, Avila M., Begot S. and Bardet J. C (2008). "Detection of Defects in Road Surface by a Vision System". Proceedings of the $14^{\text {th }}$ IEEE Mediterranean Electrotechnical Conference. Ajaccio, May 5-7, pp. 847 -851 . http://dx.doi.org/10.1109/melcon.2008.4618541

[12] Koch C. and Brilakis I. (2011). "Pothole detection in asphalt pavement images." Advanced Engineering Informatics, 25(3), pp. 507-515. http://dx.doi.org/10.1016/j.aei.2011.01.002

[13] Prathiba T., Thamaraiselvi M, Mohanasundari M, Veerelakshmi R. (2015). "Pothole detection in road using image processing." International Journal of Management, Information Technology and Engineering, 3(4), pp. 13-20.

[14] Miller J.S and Bellinger W.Y (2003). "Distress identification manual for long term pavement performance program." U.S department of transportation. Federal Highway Administration, Virginia, pp 5-19.

[15] Radopoulou S.C and Brilakis I. (2015). "Patch detection for pavement assessment." Journal of Automation in Construction, 53, pp. 95-104. http://dx.doi.org/10.1016/j.autcon.2015.03.010

[16] Oostdijk A., van Persie M., Noorbergen H.H.S. and van Rijn J.W. (2008). "Multi scale object based detection and classification of roads and vehicles in high resolution optical satellite imagery." GEOBIA 2008 conference on GEOgraphic Object Based Image Analysis for the 21st Century, University of Calgary, August 05-08. XXXVIII-4/C1, 1682-1777.

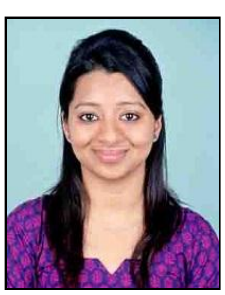

A. Ankita Khatri, is a PhD Scholar at PEC University of Technology (Formally, Punjab Engineering Collage), Chandigarh. She did her masters in Highway/ Transportation Engineering from PEC University of Technology and her area of research was assessment of deterioration on road surface. She has worked as an assistant Professor at K.R Manglam University, Gurgaon. She attended symposium and summer school organized by ISPRS at China. She has published 7 papers in National/ International journals and conferences. She has presented a poster at IIT Bombay. She is a member of India Society of Remote Sensing (ISRS). 


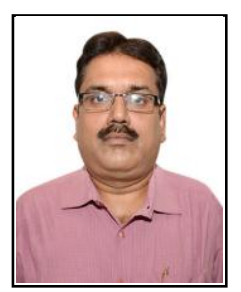

B. Dr. Umesh Sharma, is Associate Professor of Civil Engineering at PEC University of Technology (Formally, Punjab Engineering Collage), Chandigarh. He did his doctorate from PEC university of Technology. Dr Sharma has more than 25 years of academic and research experience, during which he authored more than 100 papers in journals, conferences and seminars. $\mathrm{He}$ is a member of Institution of Engineers (India), Indian Road congress, The institute of Urban Transport and Indian Society for Technical Education. 